\title{
In Memory of Professor Tamotsu Kondow Great pioneer and ambassador in nano-material science
}

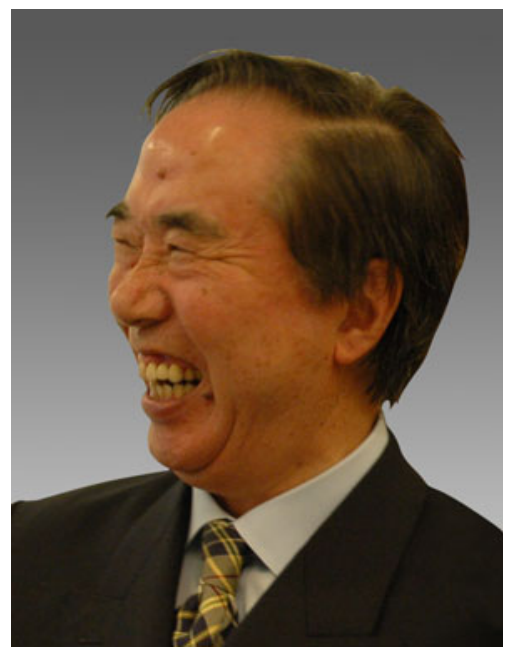

Tamotsu Kondow passed away on May 25th, 2009 at the age of 72. This foreword is the homage to Tamosu Kondow for his great achievements in science and international collaboration.

Tamotsu Kondow was born on November 19, 1936 in the present Korean region. He gained his Ph.D. degree in 1967 at the University of Tokyo under the supervision of Professor Hiroo Inokuchi where he spent 30 years at the University of Tokyo devoting his life to the development of the unprecedented field of physical chemistry. In 1997 he retired from his post as a professor of the department of chemistry and soon after, was invited to join the Toyota Technological Institute as director of the Cluster Research Laboratory, retaining high research activity until his decease. He published over 300 papers in well established journals such as Journal of Physical Chemistry, Journal of Chemical Physics and Physical Review Letters. Tamotsu Kondow was highly regarded as a pioneer in the chemistry of clusters, elucidating the size-dependence of their electronic structures and chemical reactivity. Among his brilliant achievements, two examples of cluster research conducted by Tamotsu Kondow and his collaborators will be briefly described.

\section{Soft electron attachment to clusters}

In the 1980's, many nano-scientists attempted the challenge of the anion cluster formation in order to understand the threshold point of the cluster size needed to reach positive electron affinity.

The Tokyo University group lead by Tamotsu Kondow utilised electron transport from highly excited Rydberg state rare gas atoms to target clusters where extremely slow electron from an Rydberg state atom to the cluster with low electron affinity takes place with large cross section. This method prevailed in the worldwide community of nano-cluster research and his works on this item were cited by many other groups [1-3].

\section{Nano-wedge effect in cluster-surface reaction}

One of the pronounced features of nano-sized clusters is the energetic and structural fluctuation characteristic of small finite systems. Chemists in synthetic research share common empirical rule that chemical reactions in solution are 
sensitive to the choice of the solvent. Tamotsu Kondow's group showed for the first time clear consequence of solvent induced chemical reaction where an $\mathrm{I}_{2}$ anion dissociates into $\mathrm{I}$ and $\mathrm{I}^{-}$atoms by the surrounding solvent molecules. In this dissociative reaction, a wedge effect in which a $\mathrm{CO}_{2}$ molecule as solvents in the vicinity of the mid point of the $\mathrm{I}_{2}^{-}$ bond splits the $\mathrm{I}_{2}^{-}$bond as if a piece of wood is split by a hammer thrust against a wedge [4-6].

Because of these achievements, he was honoured recipient of an Alexander von Humboldt Research Award in 2004 entitled "Structure and reactivity of clusters studied by mass spectrometry and laser spectroscopy".

In addition to his scientific achievements, Tamotsu Kondow established a broad international network of physical chemists including nano-material scientists and scientists in reaction dynamics. At any international conference, he was one of the key persons to take the leadership of the conference. He was the first Japanese chemist who joined ISSPIC since the beginning of this important symposium. He also organised many international conferences including the Genesis Research Institute Conference on clusters in 2006 and on reaction dynamics in 2008 sponsored by the Toyota Motor Corporation. Many distinguished scientists from foreign countries were very much impressed by the large scale nano-science conducted by his group at his laboratory in Tokyo whilst simultaneously enjoying his warm hospitality at his home in Chiba. In a practical sense, Tamotsu Kondow opened a door in Japan for many foreign researchers and as we know from the words of many of his friends "Tamotsu was an ambassador".

All the friends of Tamotsu and his students miss him and pray for the soul of Tamotsu Kondow.

Koji Kaya

RIKEN, Deputy Director

of the Next-Generation

Supercomputer R\&D Center.

\section{References}

1. T. Kondow, K. Mitsuke, J. Chem. Phys. 83, 2612 (1985)

2. T. Kondow, J. Phys. Chem. 91, 1307 (1987)

3. T. Nagata, T. Kondow, Y. Yamamoto, S. Hamakawa, K. Azami, Int. J. Mass Spectrom. Ion Proc. 123, 217 (1993)

4. H. Yasumatsu, A. Terasaki, T. Kondow, J. Chem. Phys. 106, 3806 (1997)

5. U. Even, T. Kondow, R.D. Levine, T. Raz, Comments At. Mol. Phys. D 1, 1 (1999)

6. H. Yasumatsu, T. Kondow, Rep. Prog. Phys. 66, 1783 (2003) 